DEPARTMENT OF THE INTERIOR

U. S. GEOLOGICAL SURVEY

\title{
SEISMICITY MAP OF THE STATE OF NEW YORK
}

By C. W. Stover, B. G. Reagor, L. M. Highland, and S. T. Algermissen 